\title{
User Satisfaction of Environmental Quality in University Buildings
}

\author{
Y. Erbil*, F. Senkal Sezer ${ }^{1}$
}

\begin{abstract}
In this study, user satisfaction with environmental quality in university buildings are investigated. The buildings that were selected for the study are the School Medicine, Veterinary School and Faculty of Agriculture buildings located at Uludag University Görükle Campus, Bursa, Turkey. A user satisfaction questionnaire developed by the authors was used to evaluate the level of satisfaction of the users in these buildings. The key themes selected were design - planning, physical environmental control, and social environment parameters. Design - planning parameter is evaluated by accessibility and reachability criteria; physical environmental control parameter is evaluated by thermal comfort, audial comfort and visual comfort criteria; and social environment parameter is evaluated by service areas and socializing criteria. The survey form, which is based on a Likert type was applied to 100 users in each building, reaching a total of 300 users. The data collected was analyzed by percentages. According to the research results, the proximity of buildings to the center of the campus, ability to easily access different storeys in buildings, ensuring thermal comfort conditions are created, not using artificial air conditioning, blocking noise from external and internal sources, fulfilling visual comfort conditions, adequate number of wet areas and car parks, establishment of eating, drinking and resting spaces, spaces for social interaction and adequate landscaping and green areas and the ability to effectively use open spaces are among the factors that influence user satisfaction in buildings.
\end{abstract}

Keywords: environmental quality, user satisfaction questionnaire, university buildings

\section{Introduction}

Physical and social environments, where students receive training activities are important to ensure highest level of benefit from education services. Parameters such as number of users in a building, colors used, organization of space, hygiene, aesthetics, heat, sound and lighting conditions can be listed among the physical environment criteria for education buildings. Research has shown that these conditions not only influence education activities but also the social and communication behaviors of students (1).

Collet da Graça et al. (2) and Boneh (3) have studies environmental comfort conditions in education buildings. There are many studies that focus on the connection between physical conditions of education buildings and learning. Gifford (4) and Yannas (5) exist establishing a relationship between the physical comfort conditions in schools and the learning capacity of students. Garret (6) 
suggest that acoustic, heat and temperature, size of spaces, lighting, and ventilation factors have an impact on the academic achievement of students. Mendell and Heath (7), Wargocki and Wyon, (8) increased classroom temperatures, Bakó-Biró et al. (9) low ventilation rates can have a negative impact on schoolwork performance and health of students. Edwards (10) indicate that when physical conditions of school buildings improve the academic achievement of students also improve. Overbaugh (11) indicates that trainers have lower efficiency in case of heating, cooling and ventilation problems exist in classrooms that are very crowded and small.

Narucki (12), Chan (13), Sleegers et al. (14) studies the impact of planning in education buildings on academic achievement. Clements-Croome et al. (15), Tippayawong et al. (16), Khedari et al. (17) carried out studies on indoor air quality and ventilation. Avsar and Gonullu (18), Elmallawany (19) have studied on sound insulation, acoustics and noise. Meklin et al. (20) has studied the impact of humidity and moisture. Krüger and Dorigo (21) and Carter (22) studied the impact of daylight and natural lighting for creating optimum comfort conditions. There are many studies that used POE (post occupancy evaluation) method for researching physical environmental quality. Zagreus, Huizenga, Arens, and Lehrer (23) indicate that the information gathered by post occupancy evaluation method will make a positive impact in improving indoor physical environmental quality. Similarly, Nawawi and Khalil (24) indicate that post occupancy evaluation method can be used to define performance parameters perceived by users. Watson (25) stated that POE can identify ways to improve building design, performance.

University buildings are places where education and research activities are carried out at the same time. Creating physical comfort conditions in university buildings and designing them to ensure socializing will provide a supportive setting for a high quality education. Although there are many studies that examine education buildings from the viewpoint of satisfaction levels of the physical and social environment, the number of studies examining university buildings are relatively low. This study aims to contribute to the literature in this field.

\section{Methodology}

The goal of this study is determining the parameters that influence physical environment quality in university buildings from the viewpoint of user satisfaction. It is believed that the research results will guide buildings to be designed and new arrangements in existing buildings in the campus. 


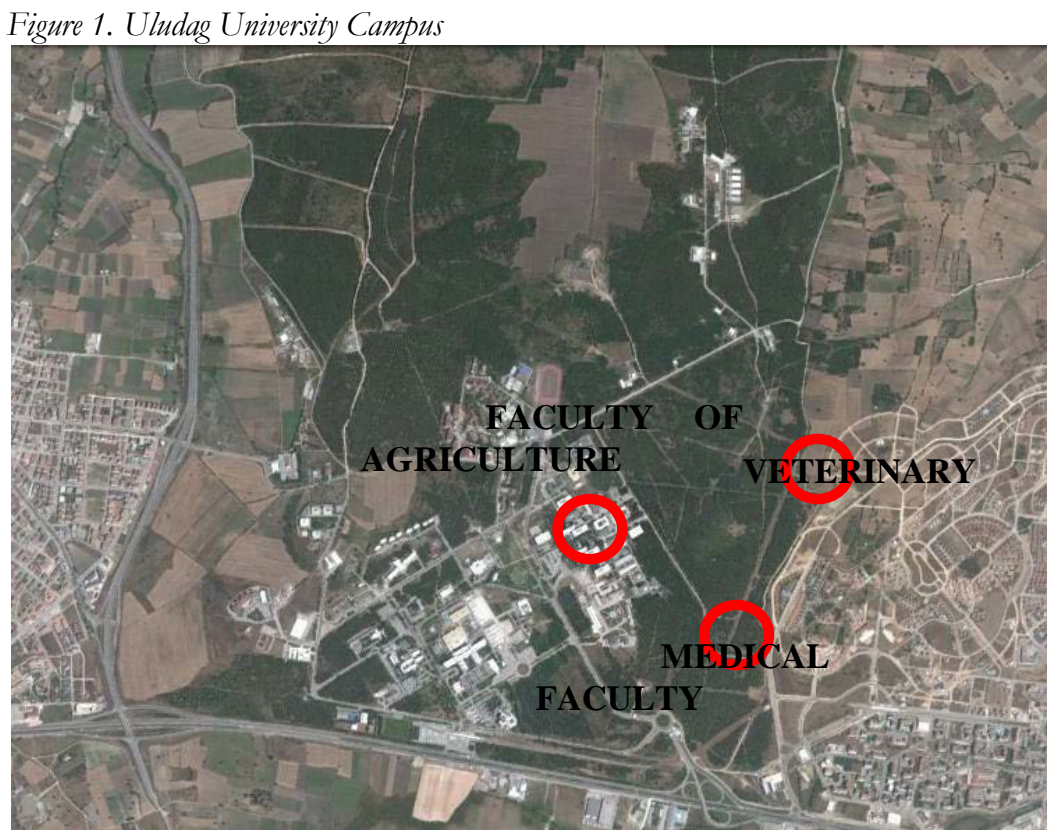

The buildings that were selected for the study are the School Medicine, Veterinary School and Faculty of Agriculture buildings located at Uludag University Görükle Campus, Bursa, Turkey (Figure 1). The building of the Medical Faculty (Figure 2) was inaugurated in 1973. The building is made of concrete and has 4 storeys. Classrooms face north west, north east, south west, and south east. The building is located at the north east and 200 meters from the center of the campus. The building of the Agriculture Faculty (Figure 3) was inaugurated in 1981. The building is made of concrete and has 3 storeys. The classrooms face east, west, north and south. The building is located at the north west and 1 kilometer from the center of the campus. The building of the Veterinarian Faculty (Figure 4) was inaugurated in 2002. The building is made of concrete and has 4 storeys. Classrooms face north west, north east, south west, and south east. The building is located at the north east and 600 meters from the center of the campus. There are classrooms, amphitheaters, computer labs, working halls, conference halls and various laboratories in the education buildings in the scope of this study. There are rooms for academia and administrators, wet areas, stairs, and circulation areas for common usage. 
Figure 2. Medical Faculty Building
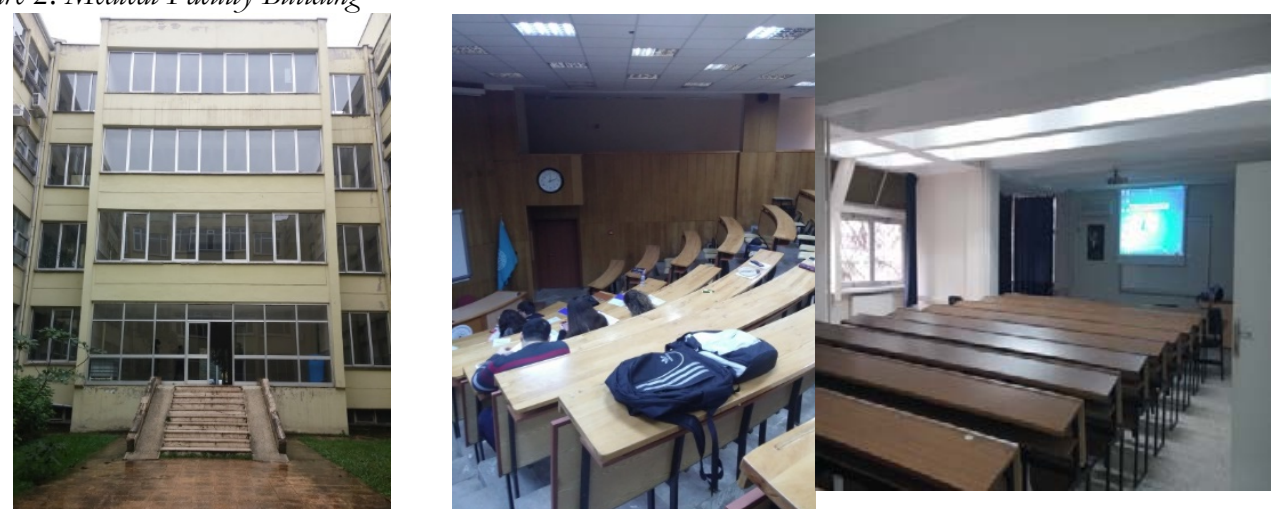

Figure 3. Agriculture Faculty Building
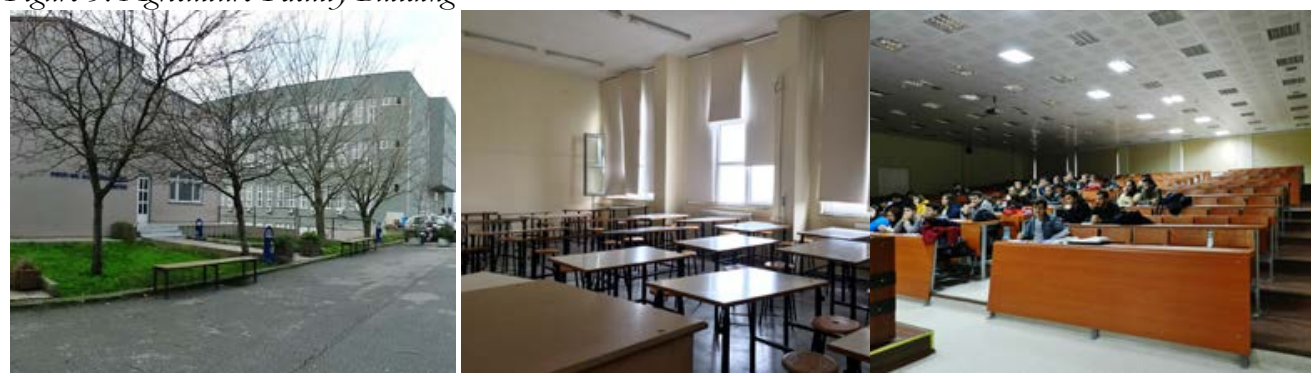

Figure 4. Veterinary Faculty Building
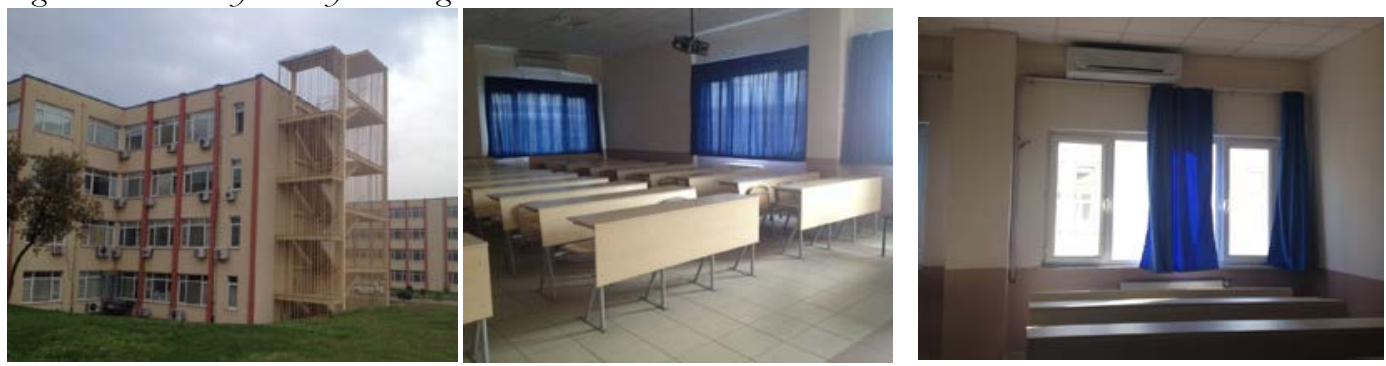

Interviews were carried out with users of the buildings, who were selected randomly, between 12.00 and 16.00 in weekdays. The study reached 100 people in each building, totaling to 300 people. In this study Post Occupancy Evaluation (POE) method was used to collect data. This method is frequently used to use current buildings more efficiently and to guide designs for new buildings. With the Post Occupancy Evaluation method, it is possible to determine problems and solutions in buildings in a short period of time, improve feedback related to building performance and area usage, achieve high cost savings during construction and the lifecycle of buildings, ensure long term improvements in 
building performance, create a knowledge source for databased, standards and criteria (26).

Table 1. Evaluation Results of Building Usage of Students

\begin{tabular}{|c|c|c|c|c|c|c|c|c|}
\hline \multirow{2}{*}{\multicolumn{2}{|c|}{ Elements of Performance }} & & \multicolumn{6}{|c|}{ Faculty of Faculty of Veterinaria } \\
\hline & & & $S$ & $\mathrm{D}$ & S & $\mathrm{D}$ & S & $\mathrm{D}$ \\
\hline \multirow{6}{*}{ 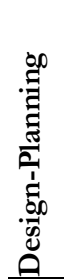 } & \multirow{3}{*}{ Transportability } & Pedestrian access in campus & 14 & & & -56 & & -14 \\
\hline & & Perception of building entrance & 16 & & 19 & & 7 & \\
\hline & & Location of education spaces & 23 & & 50 & & 56 & \\
\hline & \multirow{3}{*}{ Accessibility } & Accessibility between storeys & & -78 & & -109 & 13 & \\
\hline & & Circulation areas & 5 & & 22 & & 31 & \\
\hline & & Ease of access to units & 45 & & 8 & & 81 & \\
\hline \multirow{9}{*}{ 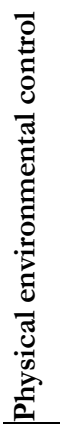 } & \multirow{3}{*}{ Thermal comfort } & Indoor temperature in summers & & -3 & & -6 & 5 & \\
\hline & & Indoor temperature in winters & & -8 & & -8 & 51 & \\
\hline & & Usage of artificial air conditioners & & -60 & 74 & & 58 & \\
\hline & \multirow{3}{*}{ Audial comfort } & Audial comfort & 2 & & 11 & & & -18 \\
\hline & & Noise from instalments & 2 & & & -20 & & -65 \\
\hline & & Exterior noise problems & 12 & & & -27 & & -48 \\
\hline & \multirow{3}{*}{ Visual comfort } & Natural lighting & 1 & & & -53 & 15 & \\
\hline & & Artificial lighting & & -64 & & -67 & & -68 \\
\hline & & Color selection & 10 & & 11 & & 41 & \\
\hline \multirow{6}{*}{ 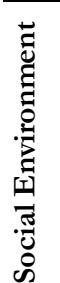 } & \multirow{3}{*}{ Service areas } & Food, beverage, resting areas & & -79 & & -42 & & -137 \\
\hline & & Wet areas & & -2 & 43 & & 58 & \\
\hline & & Car parks & & -38 & & -4 & & -19 \\
\hline & \multirow{3}{*}{ Socialization } & Usage areas fit for social interaction & & -44 & & -22 & & -40 \\
\hline & & Open space usage & & -22 & & -29 & & -42 \\
\hline & & Green areas fit for social interaction & & -21 & 16 & & & -50 \\
\hline
\end{tabular}

In the scope of this study the authors have, based on the literature analysis, first defined the key concepts to measure physical environmental quality, and then carried out a pilot study at different location of the university campus with a total of 50 students using face to face interviews. The goal of this pilot study was to define the main factors of university buildings that influence the satisfaction levels of its users. In the scope of this pilot study some of the concepts that were defined previously were eliminated and the main parameters were determined. These parameters are design - planning, physical environmental control, and social environment. Later a User Satisfaction Questionnaire was prepared which evaluates design - planning parameter with accessibility and reachability criteria; physical environmental control parameter with thermal comfort, audial comfort and visual comfort criteria; and social environment parameter with service areas and socializing criteria. All of the expressions in the study were arranged with a 
Likert type scale of five and the results are presented with charts. During the evaluation user views were scores with; very satisfied 2 , satisfied 1 , neither satisfied nor dissatisfied 0 , dissatisfied -1 , very dissatisfied -2 , can't choose: 0 , and + results were collected under "Satisfied" and - results were collected under "Dissatisfied" headings. In accordance with these data the level of comfort score was voted within -2 and +2 . In this regard the findings from this study is summarized in Table 1.

\section{Results}

Students participated in this study were aged between 18-24. When demographic data is examined $50 \%$ of the participants from the Faculty of Medicine were males and $50 \%$ were females; $42 \%$ of the participants from the Faculty of Agriculture were males and $58 \%$ were females, and $58 \%$ of the participants from the Veterinarian Faculty were males and $42 \%$ were females.

In the first part of the questionnaire the design - planning parameter was evaluated with two criteria, namely accessibility and reachability. For the reachability criteria, pedestrian access in the campus, perception of building entrances, and the location of education buildings were evaluated. The results obtained are shown in Figure 5.

Figure 5. User views based on transportability

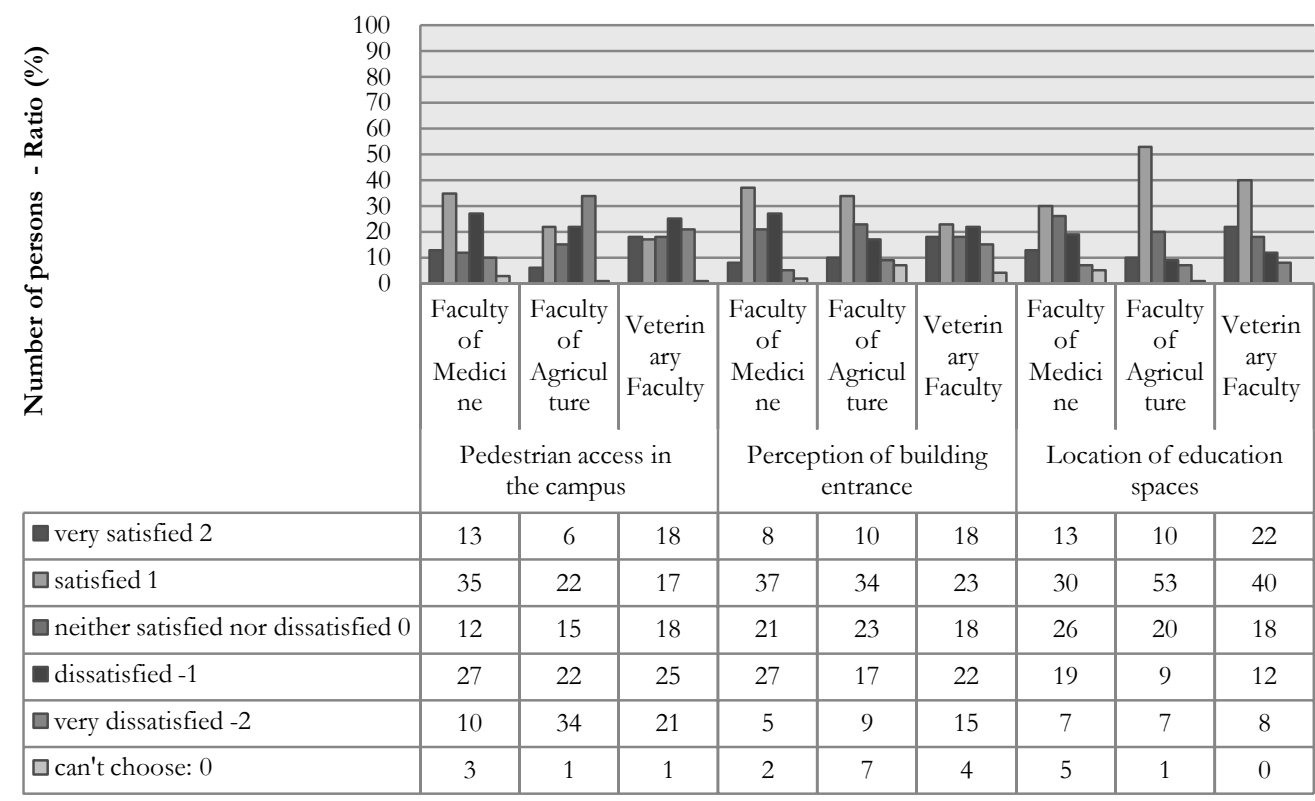


When the satisfaction levels from pedestrian access in the campus is evaluated it is seen that satisfaction levels drop when the distance of buildings from the center of the campus increases. It is seen that the distance of faculty buildings from social areas such as cafeteria, library, and conference hall has an impact on user satisfaction. When the perception of building entrances is considered, it is seen that users are satisfied from all buildings. The location of building entrances, niches or bossages, eaves, outdoor space arrangements, information provided at the entrance axis and similar design approaches have an impact on user satisfaction. When satisfaction is evaluated from the viewpoint of the location of classrooms inside the buildings it has been seen that users of all three buildings were satisfied. Buildings which don't have many storeys and are connected to each other directly and are designed with an easily comprehended access system have a positive impact on user satisfaction.

Accessibility between stories, circulation areas and ease of access to units were evaluated as accessibility criteria. The results obtained are shown in Figure 6.

Figure 6. User views based on accessibility

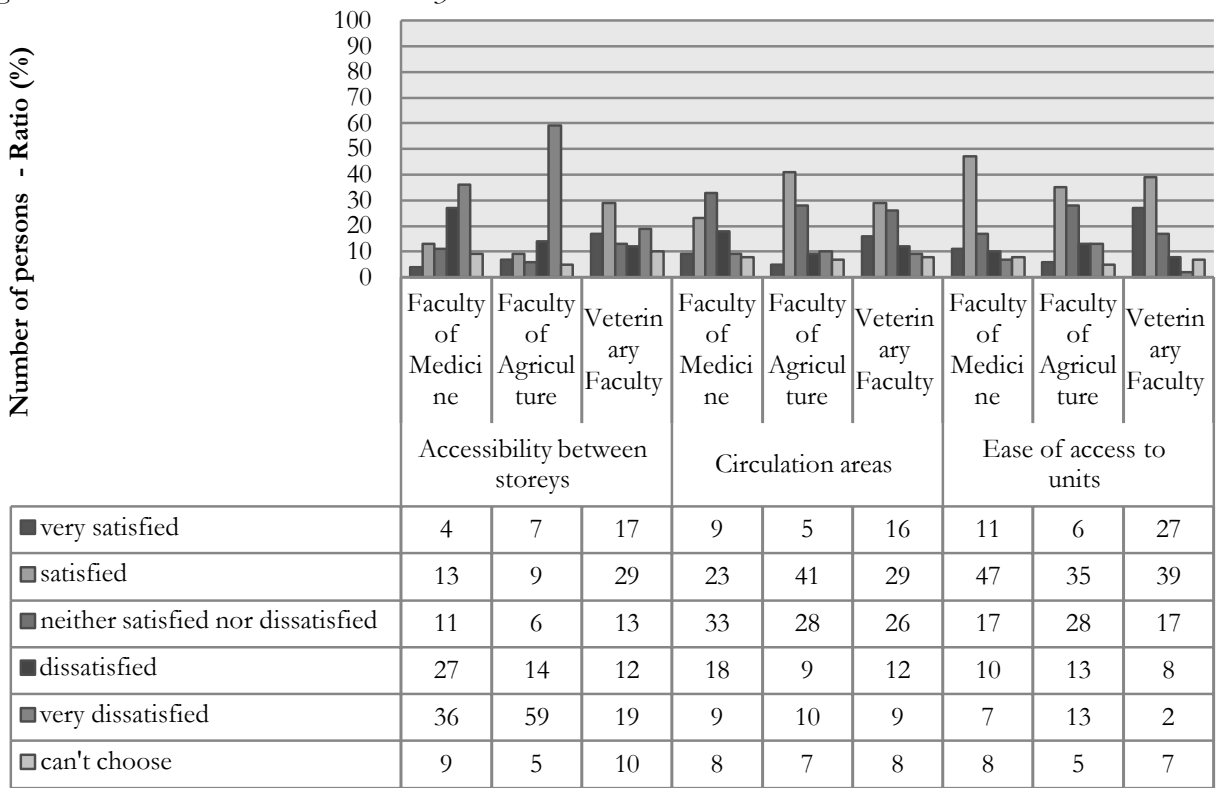

When the level of satisfaction is evaluated from the accessibility between stories criteria it was seen that satisfaction dropped in buildings where accessibility between stories is not provided via elevators. When the level of satisfaction is evaluated from the circulation criteria it was seen that the users of all three buildings were satisfied and designing wide and spacious circulation areas has a positive impact on user satisfaction. When the level of satisfaction is evaluated from the ease of access to units it was seen that users of all three buildings were 
satisfied and that user satisfaction increased when it is possible to access different units in a building without leaving the building.

In the second part of the questionnaire thermal, audial and visual comfort criteria related as the physical environment control parameter were evaluated. Indoor temperature in the summer, indoor temperature in the winter and usage of artificial air conditioners were evaluated as thermal comfort criteria. The results obtained are shown in Figure 7.

Figure 7. User views based on thermal comfort

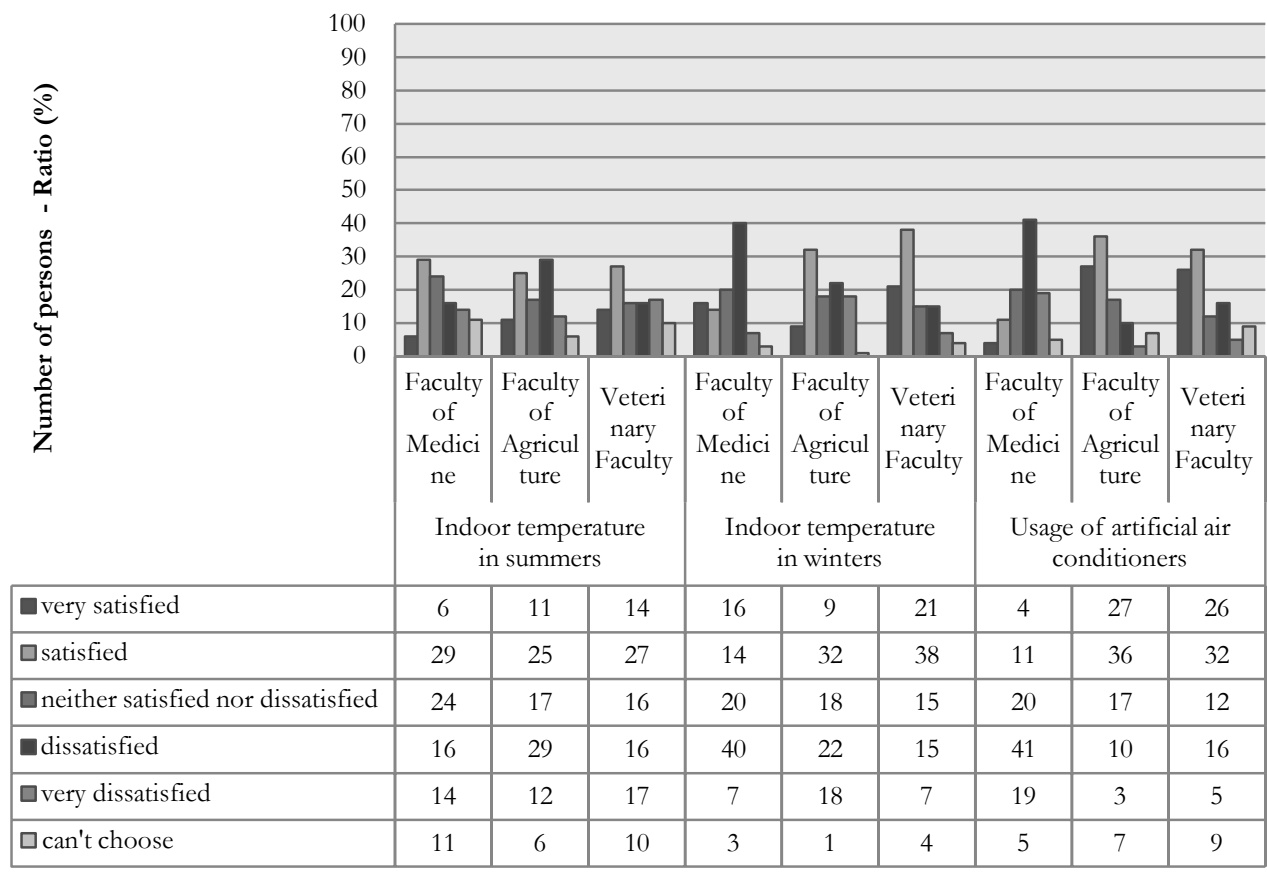

When the level of satisfaction is evaluated from the indoor temperature in the summer criteria it is seen that the direction of classrooms has an impact on satisfaction levels. When the level of satisfaction is evaluated from the indoor temperature in the winter criteria it is seen that satisfaction levels are positively influenced when buildings have smaller circulation areas and where heat insulation is better. When the level of satisfaction is evaluated from the artificial air conditioner usage it is seen that high number of users and inadequate natural ventilation have a negative impact on user satisfaction.

Indoor audial comfort, outdoor audial comfort and perceived installation noise were evaluated as audial comfort criteria. The results obtained are shown in Figure 8. 
Figure 8. User views based on audial comfort

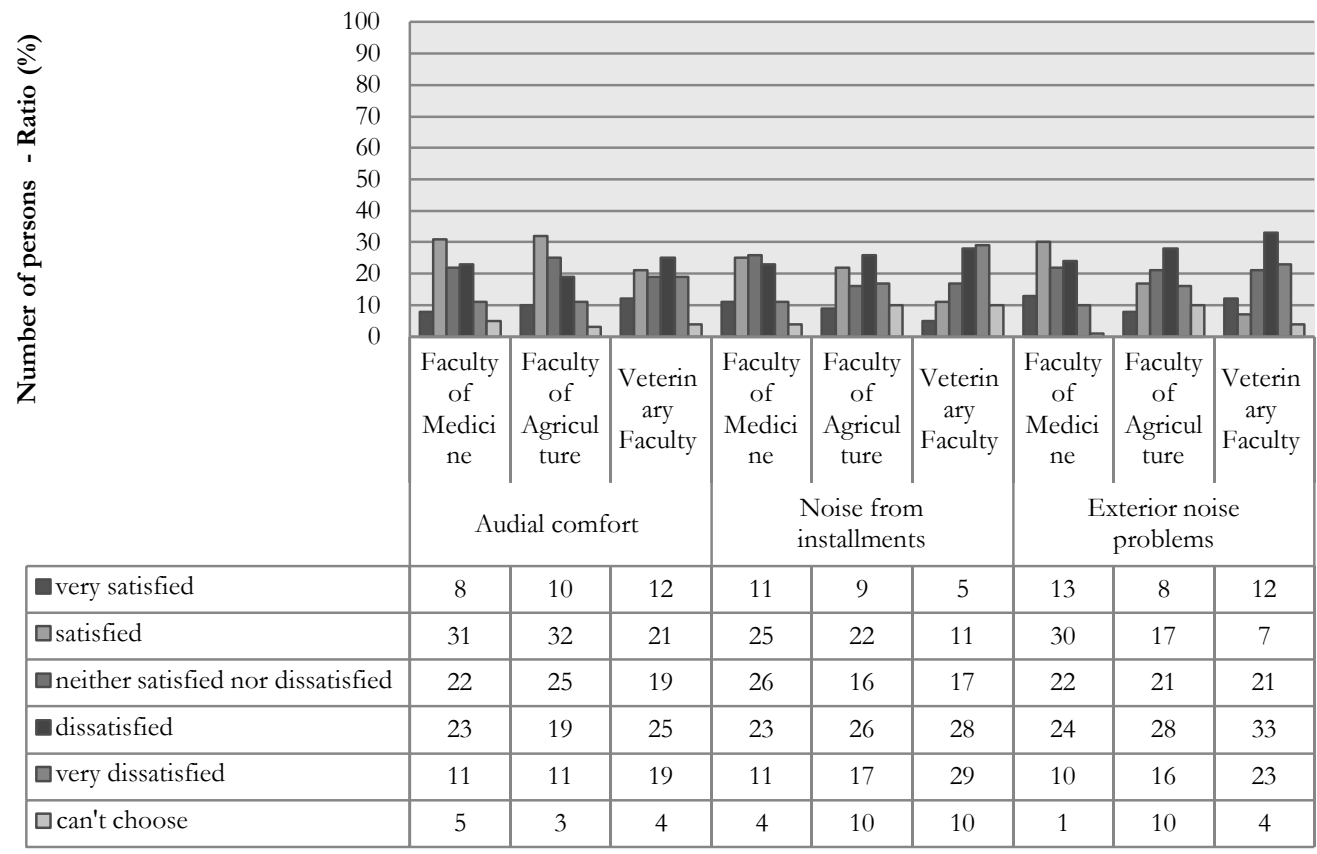

When we look at the indoor audial comfort levels we can see that not using sound isolation materials have a negative impact on user satisfaction. When we look at the opinions on installation noise we see that noise from installations have an impact on user satisfaction. When we look at the satisfaction levels related to noise from outside we see that the number of students near education buildings increase when several buildings are close to each other, which increases noise from outside and thus have a negative impact on user satisfaction.

Natural lighting, artificial lighting and color selection were considered as visual comfort criteria. The results obtained are shown in Figure 9. The size of windows has an impact on the amount of natural lighting. Natural light entering the building was considered as inadequate by users. Users have expressed discontent with artificial lighting. Even though artificial lighting devices are used in education buildings, their usage without making necessary technical calculations and measuring the light intensity has a strong impact on user satisfaction. Level of satisfaction from building colors are close in all buildings surveyed. Users' discontent from current colors is low.

In the third part of the survey social environment parameter was evaluated with two criteria, which were service areas and socializing. Food and beverage and resting areas, we areas and car parks were evaluated as service areas. The results obtained are shown in Figure 10. Users found food and beverage and resting 
areas inadequate and the inadequateness of these areas greatly lowers the satisfaction levels of users. When the user opinions on wet areas were evaluated it has been seen that the increase of the number of users of buildings had an impact on the level of satisfaction. When the user opinions related to car parks is evaluated is has been seen that users of all three buildings were discontent and that the number of users of car parks had an impact on the level of satisfaction of users.

Figure 9. User views based on visual comfort

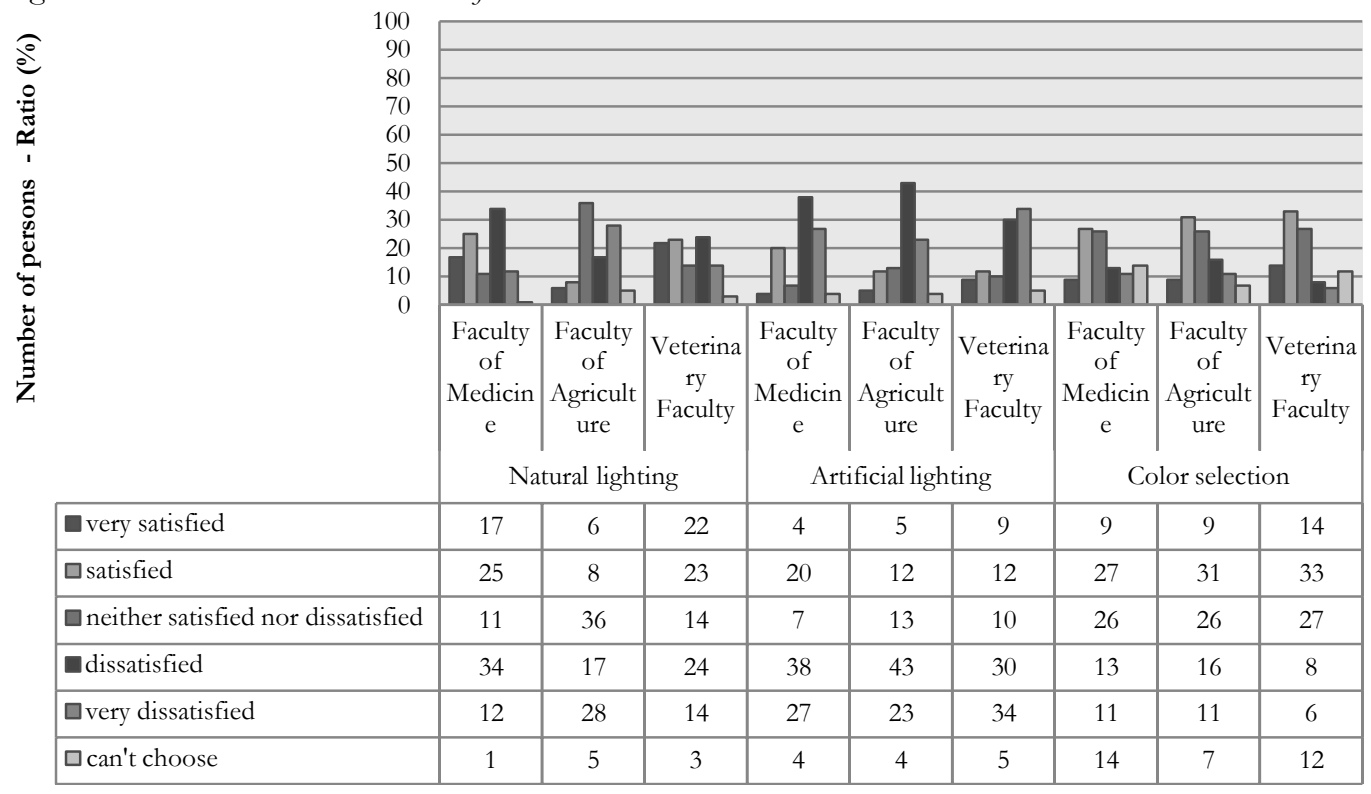


Figure 10. User views based on service areas

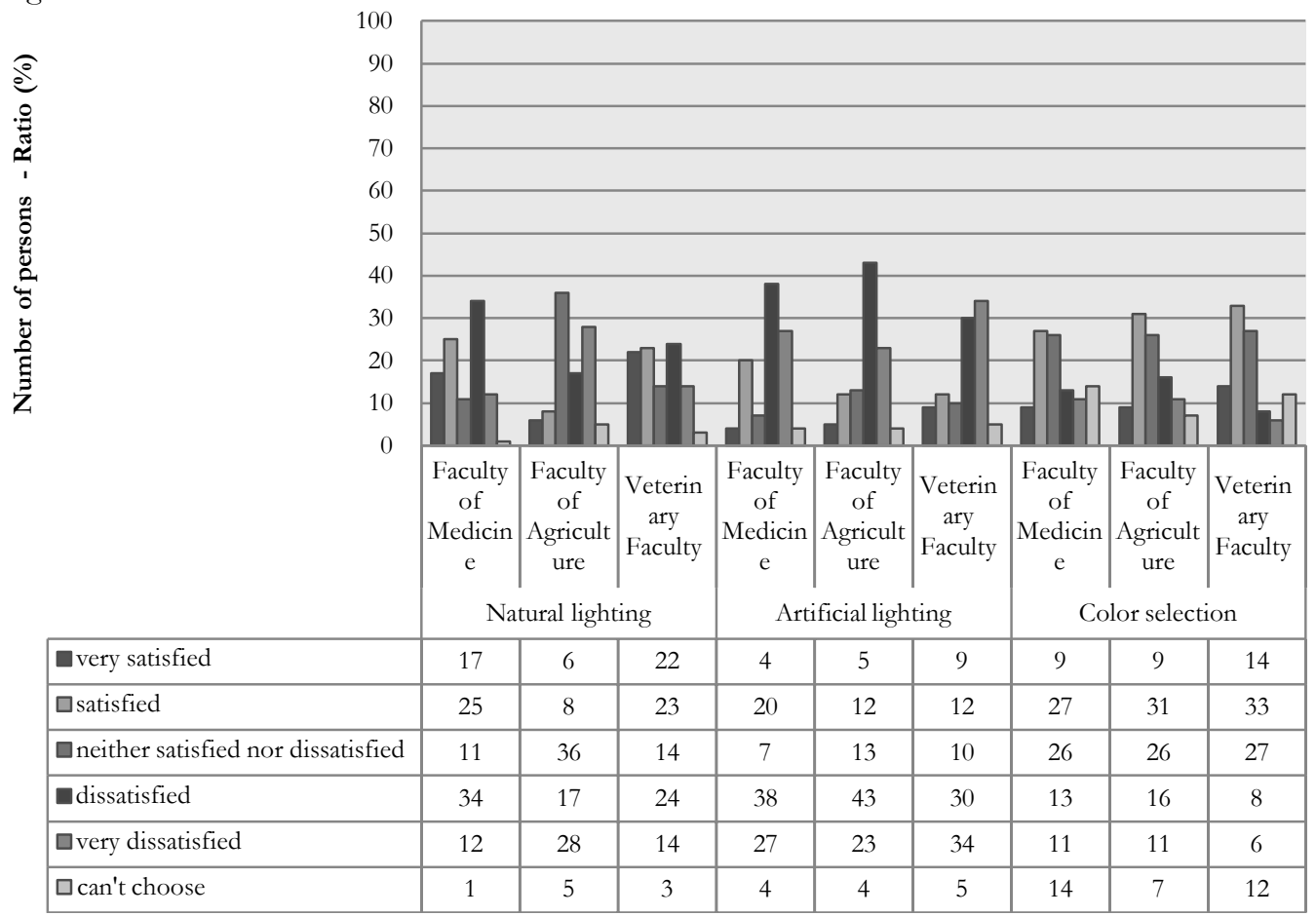

Figure 11. User views based on socialization

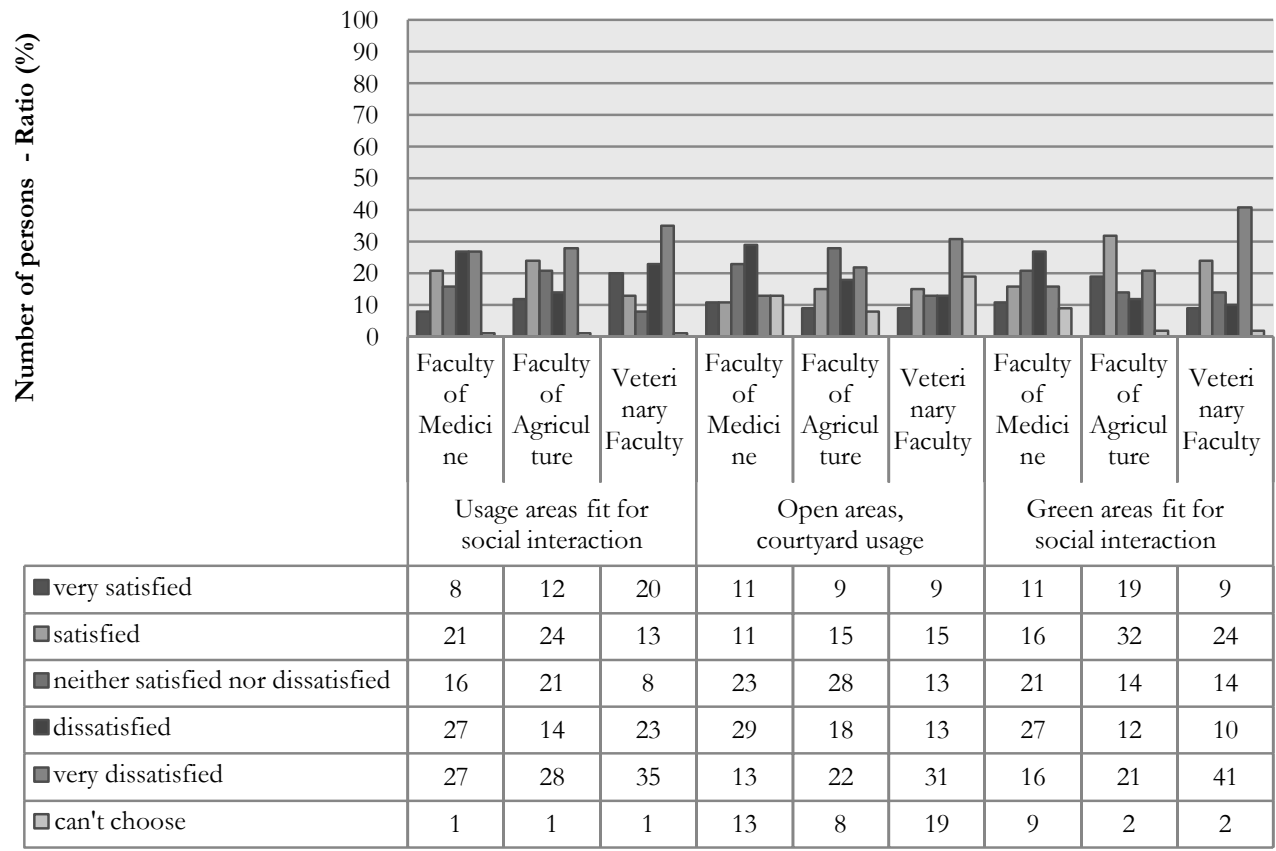


Usage areas that are suitable for social interaction, open areas and green areas with landscaping were evaluated as socialization criteria. The results obtained are shown in Figure 11. When satisfaction levels are evaluated for all three criteria it was seen that users off all three buildings have expressed their dissatisfaction. The close proximity of buildings and the majority of firm grounds around the buildings were considered as negative features. It was seen that user satisfaction is not achieved in campuses when adequate spaces for social interaction are not planned in the design of education institutions, when open spaces are not prepared based on the needs of students and when green areas are not landscaped for social interaction even if there are large green areas.

\section{Conclusion}

The results obtained are shown in Table 2. According to the results users are dissatisfied with pedestrian access in the campus under the transportability heading of design and planning; and with access between stories under the heading of accessibility. In terms of physical environmental control and under the thermal comfort heading indoor temperatures in summers and winters were not adequate; in terms of audial comfort installation noise and noise from outside were expressed as problems; and in terms of visual comfort heading artificial lighting was perceived as inadequate and improper. Users have indicated discontent with inadequate food, beverage and resting places, and car parks in relation to social environment under the services areas heading. Under the socialization heading it has been seen that places for social interaction, open areas and green areas which are not landscaped have a negative impact on user satisfaction.

In this regard is very important to define the issues that students are discontent with to establish design criteria for buildings to be designed in the future and to establish main goals for the planning of the campus in general. Factors that influence user satisfaction should be taken into consideration in university building designs for the future.

\section{References}

Özyürek, M., Sınıf Yönetimi, Karatepe Yayınları, Ankara, 2001.

Collet da Graça, V. A. and Kowaltowski, D. C. C. K. and Diego Petreche, J. R., An Evaluation Method for School Building Design at the Preliminary Phase with Optimization of Aspects of Environmental Comfort for the School System of the State São Paulo in Brazil. Building and Environment, 42(2), 984-999, 2007.

Boneh, M., Environmental Comfort in Educational Buildings — Influence of Windows and other Openings. Energy and Buildings, 4(3), 239-243, 1982.

Gifford, R., Environmental Psychology: Principles and Practice. 2 ed. Boston MA: Allyn and Bacon, 1997.

Yannas, S., Educational Buildings in Europe. In Proceedings of the III. Encontro Nacional: I Encontro Latino-Americano de Conforto No Ambiente Construído. Gramado, /RS/ p. 49-69. 1995. 
Garret, D. M., The Impact of School Building Age on the Academic Achievement of High School Pupils in the State of Georgia. Unpublished Doctoral Dissertation, University of Georgia, 1981.

Mendell, M. J. and Heath, G. A., Do Indoor Pollutants and Thermal Conditions in Schools Influence Student Performance? A Critical Review of the Literature. Indoor Air, 15(1):27-52, 2005.

Wargocki, P. and Wyon, D. P. The Effects of Outdoor Air Supply Rate and Supply Air Filter Condition in Classrooms on the Performance of Schoolwork by Children, HVAC\&R Research, 13(2):165-191, 2007.

Bakó-Biró, Z., Clements-Croome, D., Kochhar, N., Awbi, H. and Williams, M., Ventilation Rates in Schools and Pupils' Performance, Building and Environment, 48, 215-223, 2012.

Edwards, M., Building Conditions, Parental Involvement and Student Achievement in the D. C. Public School System. Unpublished Master Degree Thesis, Georgetown University, Washington, D.C., 1991.

Overbaugh, B. L. School facilities: The Relationship of the Physical Environment to Teacher Professionalism. An Unpublished Doctoral Dissertation, Texas A\&M University, 1990.

Narucki, V. D., School building Condition, School Attendance, and Academic Achievement in New York City Public Schools: A Mediation Model, Journal of Environmental Psychology, 28, 278-286, 2008

Chan, F., Public School, Public Building: The Role of the School in Building the City, Cities, 18(3), 193-197, 2001.

Sleegers, P., Van den Berg, R. and Geijsel, F., Building innovative Schools: the Need for New Approaches, Teaching and Teacher Education, 16(7), 801-808, 2000.

Clements-Croome, D. J., Awbi, H. B., Bakó-Biró, Z., Kochhar, N. and Williams, M., Ventilation Rates in Schools, Building and Environment, 43(3), 362-367, 2008.

Tippayawong, N., Khuntong, P., Nitatwichit, C., Khunatorn, Y. and Tantakitti, C., Indoor/Outdoor Relationships of Size-Resolved Particle Concentrations in Naturally Ventilated School Environments. Building and Environment, 44(1), 188-197, 2009.

Khedari, J., Yamtraipt, N., Prantintong, N., Hirunlabh, J., Thailand Ventilation Comfort Chart. Energy and Buildings, 32, 245-249, 2000.

Avsar Y, Gonullu M. T. Determination of Safe Distance Between Roadway and School Buildings to Get Acceptable School Outdoor Noise Level By Using Noise Barriers, Building and Environment, 40, 9, 1255-1260, 2005.

Elmallawany, A., Field Investigations of the Sound Insulation in School Buildings, Building and Environment, 18(1-2), 85-89, 1983.

Meklin, T., Reponen, T., Toivola, M., Koponen, V., Husman, T., Hyvärinen, A. and Nevalainen, A., Size Distributions of Airborne Microbes in Moisture-damaged and Reference School Buildings of Two Construction Types, Atmospheric Environment, 36, 39-40, 6031-6039, 2002.

Krüger, E. L., Dorigo A. L., Daylighting Analysis in a Public School in Curitiba, Brazil, Renewable Energy, 33, 1695-1702, 2008.

Carter, D. J., The lighting of the St. Mary's School, Wallasey, Building and Environment, 19(4), 209-215, 1984.

Zagreus, L., Huizenga, C., Arens, E., and Lehrer, D., Listening to the Occupants: A Web-Based Indoor Environmental Quality Survey, Indoor Air, 14, 8, 65-74, 2004.

Nawawi, A. H., and Khalil, N., Post-occupancy Evaluation Correlated with Building Occupants' Satisfaction: an Approach to Performance Evaluation of Government and Public Buildings, Journal of Building Appraisal, 4, 59-69, 2008.

Watson, C., Review of Building Quality Using Post Occupancy Evaluation, Journal of Programme Education Building, 35, 1-5, 2003.

Hassanain, M. A. Post-Occupancy Indoor Environmental Quality Evaluation of Student Housing Facilities, Architectural Engineering and Design Management, 3, 249-256, 2007. 